\title{
Longer 6-mm Diameter Stent Retrievers Are Effective for Achieving Higher First Pass Success with Fibrin-Rich Clots
}

\author{
Gaurav Girdhara Evan Epstein ${ }^{a} \quad K^{a}$ Evin Nguyen ${ }^{a} \quad$ Chelsea Gregg $^{a}$ \\ Tejashri Kumara John Wainwright ${ }^{a}$ Amon Y. Liu ${ }^{b}$ Italo Linfante ${ }^{c}$ \\ a Department of R\&D, Neurovascular, Medtronic, Irvine, CA, USA; ${ }^{b}$ AYL Consulting LLC, \\ Redwood City, CA, USA; ' Interventional Neuroradiology and Endovascular Neurosurgery, \\ Miami Cardiac and Vascular Institute, Baptist Hospital, Miami, FL, USA
}

\author{
Keywords \\ Fibrin clot - Solitaire ${ }^{\mathrm{TM}}$ - First pass success $\cdot$ Stent retriever $\cdot$ Mechanical thrombectomy . \\ Large vessel occlusion · Stroke
}

\begin{abstract}
First pass success (FPS) can be defined as in vitro retrieval of clot in a single pass during mechanical thrombectomy (MT) for acute large vessel occlusion (LVO). Despite advancements in MT technology, retrieval of fibrin-rich clots remains a challenge. Therefore, the effect of stent retriever length on FPS for fibrin-rich clots was investigated by using Solitaire ${ }^{\text {TM }} 6 \times 40$ versus $6 \times 30 \mathrm{~mm}$ devices with a balloon guide catheter (BGC) or distal access catheter (DAC) and sheath, in an in vitro model of anterior circulation neurovascular anatomy. Additionally, vascular safety of the Solitaire ${ }^{\mathrm{TM}} 6 \times 40$ versus $6 \times 30 \mathrm{~mm}$ devices was evaluated in a porcine model for differences in: luminal thrombus, inflammation, endothelial coverage, fibrin deposits, smooth muscle cell loss, elastic lamina and adventitia disruption, intimal hyperplasia, and lumen reduction, at 0,30 , and 90 days post-treatment. In vitro overall FPS was measured as: Solitaire ${ }^{\mathrm{TM}} 6 \times 40(95 \%)$ and Solitaire ${ }^{\mathrm{TM}} 6 \times 30(67 \%)$. FPS for clot location in middle cerebral artery was: (a) BGC $(6 \times 40 \mathrm{~mm}: 100 \% ; 6 \times 30 \mathrm{~mm}: 100 \% ; n=8)$; (b) DAC with 088 sheath $(6 \times$ $40 \mathrm{~mm}: 83 \% ; 6 \times 30 \mathrm{~mm}: 33 \% ; n=12)$. FPS for clot location in internal carotid artery was: (a) BGC $(6 \times 40 \mathrm{~mm}: 100 \% ; 6 \times 30 \mathrm{~mm}: 80 \% ; n=11)$; (b) DAC with 088 sheath $(6 \times 40 \mathrm{~mm}$ : 100\%; $6 \times 30 \mathrm{~mm}: 67 \% ; n=10$ ). Stent length had a significant effect (Fisher's exact test; $p<0.05$ ) on FPS. In vivo evaluation in the porcine model showed no difference in vascular safety parameters between the Solitaire ${ }^{\mathrm{TM}} 6 \times 40$ and $6 \times 30 \mathrm{~mm}$ devices $(p>0.05)$ at all time points in the study. Longer stent retrievers may be safe and effective in improving FPS for fibrin-rich clots in in vitro and in vivo models of LVO.




\section{Introduction}

Mechanical thrombectomy (MT) with stent retrievers has shown to be safe and effective for treatment of intracranial large vessel occlusion in acute ischemic stroke treatment [1-7]. First pass effect with stent retriever use has been suggested as a clinical metric of improved patient outcomes [8]. Higher fibrin content thrombi present in approximately $44 \%$ of clinical cases [9] are mechanically stiffer and typically more difficult to retrieve compared to softer red blood cell-rich clots. Recent studies have evaluated clot retrieval resistance as a function of clot composition and it has been found that stent retrievers do not engage well with high fibrin content clots $[10,11]$.

Newer-generation stent retriever devices (Solitaire ${ }^{\mathrm{TM}}$ Platinum $6 \times 40 \mathrm{~mm}$, Medtronic) are longer and larger in diameter. These modifications are hypothesized to allow the clot to engage more effectively with the stent with multiple planes of attachment at the lower range $(2-3 \mathrm{~mm})$ of diameters in the MCA (middle cerebral artery) and maintain this engagement at the higher range (3-6 $\mathrm{mm}$ ) of diameters in the ICA (internal carotid artery) during clot retrieval. In vitro benchtop methods provide a controlled and reproducible method to assess device performance characteristics with a variety of clot types [12-18] and would therefore allow a comparison of clot retrieval efficacy between device lengths of the same diameter. Even though longer stent retrievers are hypothesized to exhibit a higher clot retrieval success rate, the vascular safety of these devices in an in vivo model also needs to be assessed. Previous in vivo studies in porcine models have shown that longer devices $4 \mathrm{~mm}$ in diameter $(4 \times 40$ vs. $4 \times 20 \mathrm{~mm}$ ) are equivalent in terms of safety [19]; however, a similar comparison between the larger 6-mm diameter devices has not been conducted. Recent clinical data show higher first pass mTICI $2 b / 3$ reperfusion with longer 4-mm diameter stent retrievers [20]. However, the mechanism of the improved efficacy with longer devices and correlation with fibrin-rich clots is difficult to decipher from clinical data alone.

The purpose of this study was therefore two-fold: (a) to evaluate in vitro any differences in clot retrieval efficacy as a function of stent retriever length for $6 \times 40 \mathrm{~mm}$ versus $6 \times 30 \mathrm{~mm}$ Solitaire ${ }^{\mathrm{TM}}$ devices for the fibrin-rich clot type, and (b) to evaluate in vivo the safety of the $6 \times$ $40 \mathrm{~mm}$ Solitaire ${ }^{\mathrm{TM}}$ device compared with the $6 \times 30 \mathrm{~mm}^{\text {Solitaire }} \mathrm{T}^{\mathrm{TM}}$ device, in a porcine model.

\section{Methods}

First Pass Success: In vitro Study

First Pass Success

In the present study, we introduce first pass success (FPS) as a metric to measure in vitro clot retrieval efficacy for homogenous cylindrical fibrin-rich clots. FPS was measured as a binary outcome: 0 (fail) or 1 (pass) for each run completed. Therefore, the result is either a TICI3 recanalization (successful clot retrieval - pass) or no recanalization (no clot retrieval - fail). The result for each device is expressed as a percentage of successful clot retrievals (\% FPS).

Test Model

A silicone elastomer-based tortuous anatomical model consisting of the right ICA extending from a type 3 aortic arch with clinically relevant vessel diameters ranging from 6.5 or $5.5 \mathrm{~mm}$ in the proximal ICA to 1.5 $\mathrm{mm}$ in the M2 segment of the MCA, was used (Fig. 1). A physiological solution of water and $0.2 \% \mathrm{v} / \mathrm{v}$ soap was circulated from the ICA and the posterior communicating artery (PCOM) to the anterior cerebral artery (ACA), MCA and ophthalmic arteries (outflow) at $37 \pm 2{ }^{\circ} \mathrm{C}$ under clinically relevant pressures $(150 \pm 10 \mathrm{~mm}$ $\mathrm{Hg}$ [systolic] and $70 \pm 10 \mathrm{~mm} \mathrm{Hg}$ [diastolic]) and flow rate $(300 \pm 50 \mathrm{~mL} / \mathrm{min})$. Flow was driven with a Harvard Pulsatile Pump (Harvard Apparatus, MA, USA) operating at $60 \mathrm{bpm}$. 


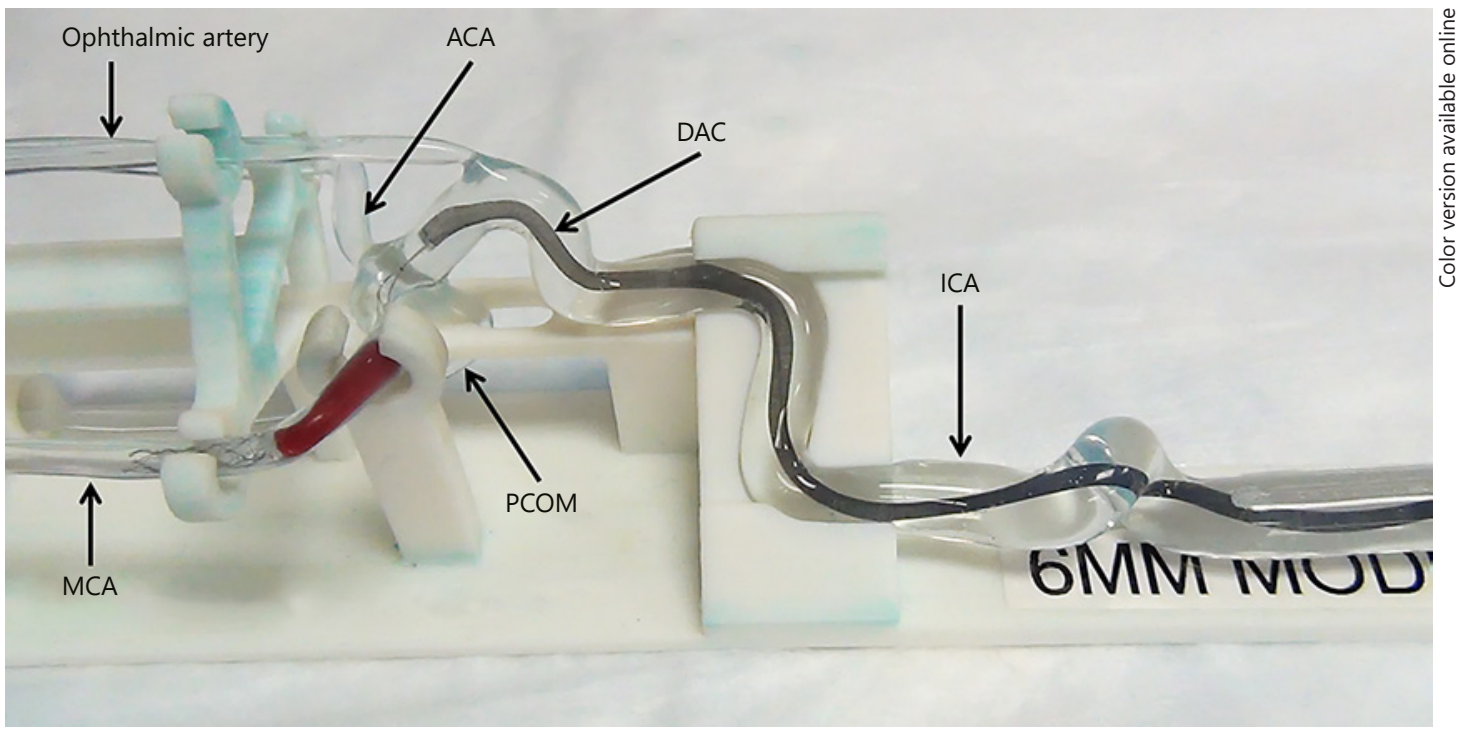

Fig. 1. Anatomical silicone model of ICA-MCA-ACA used for in vitro first pass effect study. The example shown is with fibrin-rich clot in MCA with Solitaire ${ }^{\mathrm{TM}} 6 \times 40 \mathrm{~mm}$ deployed. The 088 sheath (in proximal ICA) is not shown. PCOM, posterior communicating artery; ACA, anterior cerebral artery; ICA, internal carotid artery; MCA, middle cerebral artery; DAC, distal access catheter.

\section{Clot Analogs}

One clot analog - fibrin rich - was utilized for this study based on properties known from clinically analyzed clots [21]. The fibrin-rich clot composition consisted of a combination of porcine blood ( $3 \mathrm{~mL})$, barium sulfate $(0.25 \mathrm{~g}$ ), fibrinogen ( $4 \mathrm{~mL}$ of $10 \% \mathrm{w} / \mathrm{v}$ ), calcium chloride $(0.1 \mathrm{~mL}$ of $1 \mathrm{~m}$ stock), and thrombin ( $0.025 \mathrm{~mL}$ of $500 \mathrm{U} / \mathrm{mL}$ stock). The clot was evaluated for mechanical stiffness using a Dynamic Mechanical Analyzer (TA Instruments) per the methodology described previously to ensure that the range of values was consistent with thrombus seen clinically [21]. The modulus was found to be $0.138 \pm 0.08 \mathrm{MPa}$, on average. The desired length of the thrombi was 20 and $25 \mathrm{~mm}$ for the MCA and ICA, respectively, for the $6 \times 30$ and 6 $\times 40 \mathrm{~mm}$ devices FPS comparison. These represent the upper limits of clot lengths commonly seen at these locations [22].

\section{Clot Retrieval}

After the clot was introduced, access to and through the clot to the distal MCA was achieved using a $0.014{\text { in } \text { Avigo }^{\mathrm{TM}} \text { guidewire (Medtronic) and a Marksman }}^{\mathrm{TM}} 0.027$ in microcatheter (Medtronic). The Solitaire $^{\mathrm{TM}}$ device was delivered through the microcatheter until the distal tip of the Solitaire ${ }^{\mathrm{TM}}$ reached the end of the microcatheter and was deployed by pinning the delivery wire and withdrawing the microcatheter. The non-working lengths (proximal and distal ends of the devices) did not interact with the clot during device deployment. All experiments were conducted under full visibility of the model, clot, and device to the operators (no fluoroscopy), thereby allowing for precise deployments in all cases. After engagement with the clot, the Solitaire ${ }^{\mathrm{TM}}$ device was withdrawn into either (a) a distal access catheter (DAC; $060 \mathrm{Arc}^{\mathrm{TM}}$, Medtronic) until there was significant resistance (indicative of corking of the clot) and a sheath (Neuron ${ }^{\mathrm{TM}} 088$ MAX, Microvention) or (b) a balloon guide catheter (BGC; 9F Cello ${ }^{\mathrm{TM}}$, Medtronic). If a DAC was used, the microcatheter was removed prior to aspiration with a $60-\mathrm{ml}$ syringe. If a BGC was used, the balloon was inflated prior to retrieval of the clot to arrest flow through the ICA.

Devices and Experiments

A total of 41 thrombectomy evaluations were conducted in vitro and were randomized between Solitaire $^{\mathrm{TM}} 6 \times 30 \mathrm{~mm}(n=20)$ and $6 \times 40 \mathrm{~mm}(n=21)$ with both MCA and ICA as clot locations and both BGC or DAC with 088 sheath as access options. 
Vascular Safety: In vivo Study

Test Model and Medication

Swine was used for the animal model as the arterial anatomy, hemodynamic and coagulation properties mimic those of a human $[19,23]$. The in vivo study was conducted under an approved Institutional Review Board protocol. Eighteen Yorkshire cross swine were utilized in this study with 6 animals each at 0-, 30-, and 90 -day time points. The Solitaire ${ }^{\mathrm{TM}}$ devices $(6 \times 30$ and $6 \times 40 \mathrm{~mm})$ were deployed as per the instructions for use in the following arteries: vertebral, internal thoracic, and costocervical. The targeted vessels were $<3.0$ $\mathrm{mm}$ in diameter to ensure that the devices were deployed into worst-case vessel sizes at or below the minimum labeled vessel size. Dual antiplatelet therapy (aspirin: $81 \mathrm{mg}$ and clopidogrel: $75 \mathrm{mg}$ ) was administered orally 1-day pre-procedure for all animals to reduce the risk of procedure-related thromboembolic complications. Nifedipine (30 mg) was administered as necessary to prevent vessel spasm intra-procedure only.

Test Devices and Deployments

For one complete test, a Solitaire ${ }^{\mathrm{TM}}$ device was deployed in the vessel seven times, resheathed into the microcatheter six times at the deployment location and retrieved through the target vessel into the guide catheter three times (i.e., multiple deployments of the devices were performed at the target location to mimic a clinical worse case). Angiographic assessments of the target vessel were performed prior to and following each pass, and presence of any emboli, vessel damage, thrombus formation, and/or vasospasm were noted. No clot analogs were utilized in the in vivo testing to reduce potential variation between tests and to provide the most direct evaluation of the stent retriever on the vessel wall; this aligns with previous preclinical work performed on Solitaire ${ }^{\mathrm{TM}} 4-\mathrm{mm}$ devices [19].

Angiographic and Histopathology End Points

At $0,30 \pm 3$, or $90 \pm 3$ days following the multiple deployment and recovery testing, the animals underwent a follow-up angiogram to evaluate target vessels for stenosis, thrombus formation, and vessel damage. Animals were euthanized following angiographic evaluation, and the treated vessels were evaluated histologically for the following attributes: luminal thrombus, inflammation, endothelial coverage, fibrin deposits, smooth muscle cell loss, elastic lamina and adventitia disruption, intimal hyperplasia, and lumen reduction, and graded on a scale of 0-4 at three locations along the treated zone (Table 1).

\section{Statistical Analysis}

Statistical comparisons for in vitro FPS for Solitaire ${ }^{\mathrm{TM}} 6 \times 40$ versus $6 \times 30 \mathrm{~mm}$ were conducted with Fisher's exact test. Statistical comparisons for histological parameters between Solitaire ${ }^{\mathrm{TM}} 6 \times 40$ and $6 \times 30$ $\mathrm{mm}$ were conducted with ANOVA at the three time points $(0,30$, and 90 days). A significance level of 0.05 was used for all tests.

\section{Results}

FPS: In vitro Study

Solitaire ${ }^{\mathrm{TM}} 6 \times 40$ and $6 \times 30 \mathrm{~mm}$ FPS Comparison

FPS with the $6 \times 40 \mathrm{~mm}$ device $(95 \% ; n=20)$ was significantly higher compared to the 6 $\times 30 \mathrm{~mm}$ device $(67 \% ; n=21)$. The results are shown in Figure 2 for overall FPS and FPS by access type. FPS for clot location in MCA was: (a) BGC (6 40 mm: 100\%; $6 \times 30 \mathrm{~mm}$ : 100\%; $n=8)$; (b) DAC with 088 sheath (6 $440 \mathrm{~mm}: 83 \% ; 6 \times 30 \mathrm{~mm}: 33 \% ; n=12)$. FPS for clot location in ICA was: (a) BGC (6 $40 \mathrm{~mm}$ : 100\%; $6 \times 30 \mathrm{~mm}: 80 \%$; $n=11)$; (b) DAC with 088 sheath $(6 \times 40 \mathrm{~mm}: 100 \% ; 6 \times 30 \mathrm{~mm}: 67 \% ; n=10)$. In most cases, the clot was corked at the tip of the DAC or BGC prior to retrieval of the entire system.

\section{Vascular Safety: In vivo Study}

All animals were in good clinical health throughout the duration of the study. A gross necropsy evaluation found no thromboembolism in the heart or lungs of the animals. 
Table 1. Histopathologic evaluation attributes and grading scale

\begin{tabular}{|c|c|}
\hline Histopathologic attribute & Grading scale \\
\hline Luminal thrombus & $\begin{array}{l}\text { 0: No luminal thrombus } \\
\text { 1: (Minimal): Occupies } \sim<5 \% \text { of the lumen area } \\
\text { 2: (Mild): Occupies } \sim 5-35 \% \text { of the lumen area } \\
\text { 3: (Moderate): Occupies } \sim 35-70 \% \text { of the lumen area } \\
\text { 4: (Severe): Occupies } \sim>70 \% \text { of the lumen area }\end{array}$ \\
\hline Endothelial cell coverage & $\begin{array}{l}0:(\text { Absent): } \sim<5 \% \text { of the luminal surface } \\
\text { 1: (Minimal): } \sim 5-25 \% \text { of the luminal surface covered } \\
\text { 2: (Mild): } \sim 25-50 \% \text { of the luminal surface } \\
\text { 3: (Moderate): } \sim 50-90 \% \text { of the luminal surface } \\
\text { 4: (Complete): } \sim>90 \% \text { of the luminal surface }\end{array}$ \\
\hline Inflammation & $\begin{array}{l}\text { 0: No inflammatory response } \\
\text { 1: Minimal response } \\
\text { 2: Mild response } \\
\text { 3: Moderate response } \\
\text { 4: Severe response }\end{array}$ \\
\hline Fibrin deposits & $\begin{array}{l}\text { 0: Not present } \\
\text { 1: Minimal } \\
\text { 2: Mild } \\
\text { 3: Moderate } \\
\text { 4: Severe }\end{array}$ \\
\hline Medial smooth muscle cell loss & $\begin{array}{l}0: \text { No medial SMC loss } \\
\text { 1: Minimal } \sim<5 \% \text { medial SMC loss } \\
\text { 2: Mild } \sim 5-25 \% \text { medial SMC loss } \\
\text { 3: Moderate } \sim 25-50 \% \text { medial SMC loss } \\
\text { 4: Severe } \sim>50 \% \text { medial SMC loss }\end{array}$ \\
\hline $\begin{array}{l}\text { Disruption of the internal elastic lamina and } \\
\text { external elastic lamina }\end{array}$ & $\begin{array}{l}0: \text { No disruption } \\
\text { 1: Minimal } \sim<5 \% \text { disruption } \\
\text { 2: Mild } \sim 5-25 \% \text { disruption } \\
\text { 3: Moderate } \sim 25-50 \% \text { disruption } \\
\text { 4: Severe } \sim>50 \% \text { disruption }\end{array}$ \\
\hline Adventitia disruption & $\begin{array}{l}0: \text { No changes } \\
1 \text { : Minimal } \sim<5 \% \text { of the area with changes } \\
2: \text { Mild } \sim 5-25 \% \text { of the area with changes } \\
\text { 3: Moderate } \sim 25-50 \% \text { of the area with changes } \\
\text { 4: Severe } \sim>50 \% \text { of the area with changes }\end{array}$ \\
\hline Neointimal hyperplasia & $\begin{array}{l}0:(\text { Absent): } \sim<5 \% \text { of the luminal surface } \\
\text { 1: (Minimal): } \sim 5-25 \% \text { of the luminal surface } \\
\text { 2: (Mild): } \sim 25-50 \% \text { of the luminal surface } \\
\text { 3: (Moderate): } \sim 50-90 \% \text { of the luminal surface } \\
\text { 4: (Severe): } \sim>90 \% \text { of the luminal surface }\end{array}$ \\
\hline Lumen area reduction due to hyperplasia & $\begin{array}{l}0:(\text { Absent): } \sim<5 \% \text { of the luminal area } \\
\text { 1: (Minimal): } \sim 5-25 \% \text { of the luminal area } \\
\text { 2: (Mild): } \sim 25-50 \% \text { of the luminal area } \\
\text { 3: (Moderate): } \sim 50-90 \% \text { of the luminal area } \\
\text { 4: (Severe): } \sim>90 \% \text { of the luminal area }\end{array}$ \\
\hline
\end{tabular}

\section{Angiographic Evaluation}

No thrombus formation, emboli, or vessel wall damage was seen angiographically during any of the procedures for all devices used.

\section{Histopathologic Evaluation}

There was no significant effect of stent length on any of the histopathology parameters of the treated vessels with the $6 \times 40$ and $6 \times 30 \mathrm{~mm}$ Solitaire ${ }^{\mathrm{TM}}$ devices $(p>0.05)$. All groups 


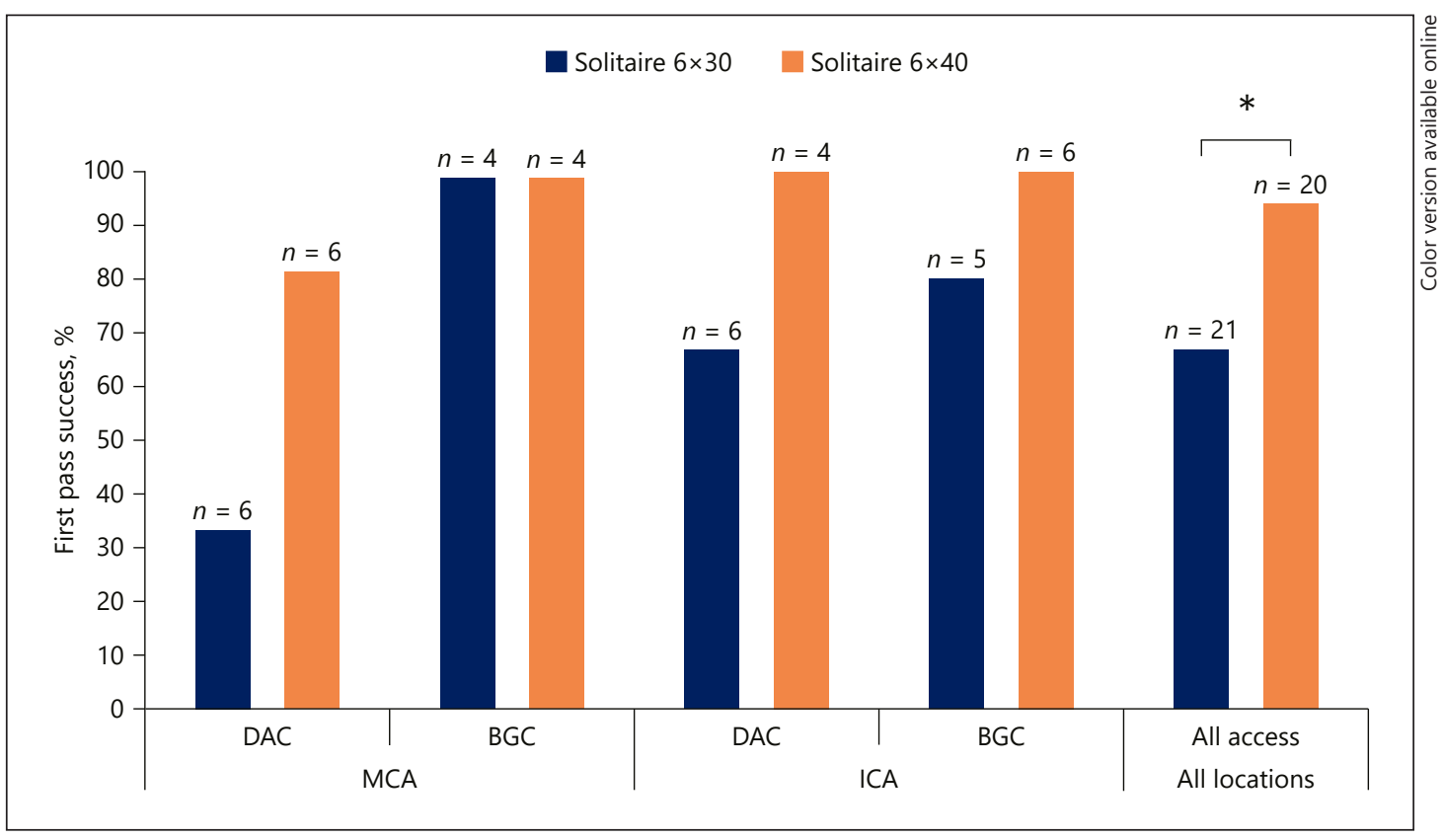

Fig. 2. First pass success of $6 \times 40$ and $6 \times 30 \mathrm{~mm}$ Solitaire ${ }^{\mathrm{TM}}$ for fibrin-rich clot retrieval with DAC and 088 sheath and BGC, for both MCA and ICA clot locations. Overall FPS for $6 \times 40 \mathrm{~mm}$ Solitaire ${ }^{\mathrm{TM}}$ is significantly higher than $6 \times 30 \mathrm{~mm}$ Solitaire ${ }^{\mathrm{TM}}(p<0.05)$.

showed minimal or no response for the following at each time point investigated: luminal thrombus, inflammation, internal elastic lamina and external elastic lamina disruption, adventitia changes.

The effect of time point was significant for the following parameters: endothelial coverage, neointimal hyperplasia, lumen area reduction, smooth muscle cell loss, and presence of fibrin deposits $(p<0.05)$. At the acute ( 0 -day) time point, endothelial denudation and slight SMC loss was noted for all devices. By the 30-day time point, all vessels had complete or nearly complete endothelialization and no SMC loss. However, at this time point, there was minimal fibrin deposition and moderate to severe neointimal hyperplasia in all vessels with mild lumen area reduction. At the 90-day time point, both treatment groups saw a significant increase in the lumen area. These results are shown in Figure 3.

\section{Discussion}

The present data seem to indicate that increase in length of the 6-mm diameter Solitaire ${ }^{\mathrm{TM}}$ device may improve FPS for fibrin-rich clot retrieval without increasing the risk of vessel damage. Regarding safety, the $6 \times 40 \mathrm{~mm}$ Solitaire ${ }^{\mathrm{TM}}$ device showed no significant effect of stent length on any in vivo vascular parameters evaluated in a porcine model compared with the $6 \times 30 \mathrm{~mm}$ Solitaire ${ }^{\mathrm{TM}}$ device. No serious adverse events were noted angiographically during the procedures and during the 90-day survival phase of the study. Additionally, the histopathology results were similar to those seen in a previous study of 4-mm Solitaire ${ }^{\mathrm{TM}}$ devices and did not show any significant health risks $[19,24]$. The effect of time post-treatment was significant for some vascular parameters - in particular the endothelial coverage - at the target location of the procedure. This has been reported previously with MT [19] and is known not to have long-term clinically significant effects on the vessel [23-25]. Despite some 


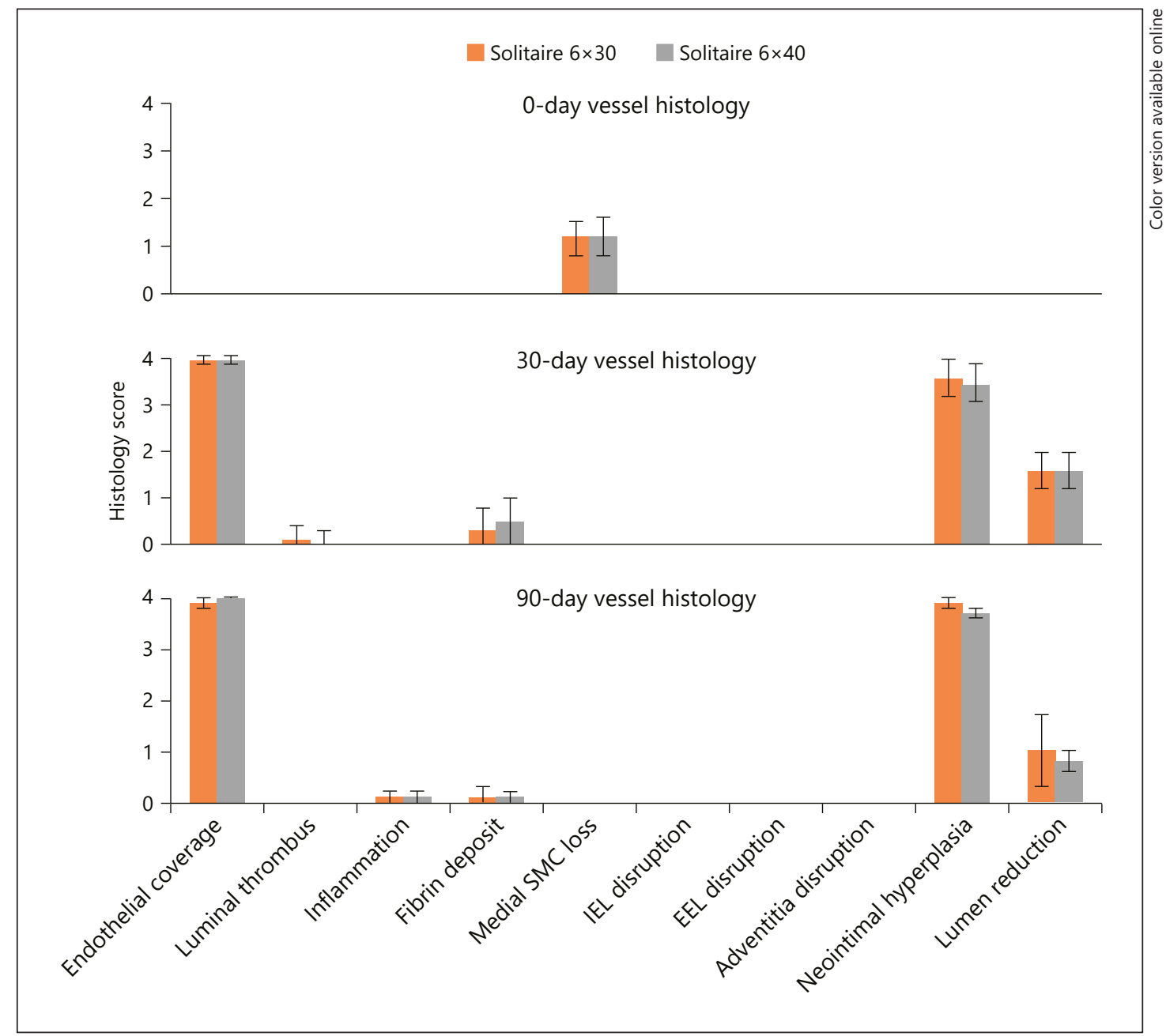

Fig. 3. Summary of 0-, 30-, and 90-day vessel histology scoring for $6 \times 40$ and $6 \times 30 \mathrm{~mm}$ Solitaire ${ }^{\mathrm{TM}}$ devices following multiple deployment and retrieval passes in a porcine model. No statistical difference was found due to stent length for any time point $(p>0.05)$. IEL, internal elastic lamina; EEL, external elastic lamina; SMC, smooth muscle cell.

recent evidence collected in an animal model suggesting that alternative endovascular techniques may cause less vessel damage [26], a direct comparison in a clinical trial has shown no difference in adverse events when compared to MT with the use of stent retrievers [27].

Some limitations with the animal model are as follows: (a) the tortuosity of the target vessels was much lower than typically observed in the ICA and MCA; (b) the in vivo testing was also performed with no clot analog in order to most directly compare the stent effects on smaller-sized vessels alone (maximize the contact of the stent and the vessel, a worst-case scenario); (c) evaluation of the treated vessels was also limited to a 90-day window, which provides adequate information on the immediate effect of treatment and the subsequent near-term vascular healing process; and (d) the porcine arterial vessels in the in vivo study may have structural differences compared with human intracranial arteries.

Benchtop evaluation of FPS using a fibrin rich clot with the $6 \times 40$ versus $6 \times 30 \mathrm{~mm}$ Solitaire $^{\mathrm{TM}}$ devices demonstrated that there is a significant increase in FPS $(p<0.05)$ when using longer lengths of these devices. This is evident primarily with the fibrin-rich clot (clinical occurrence in approximately $44 \%$ of cases [9]) which tends not to engage as effectively with 
the stent retrievers as red blood cell-rich or mixed clot compositions due to higher mechanical stiffness [21] and possibly differences in friction [10]. The longer-length devices provide better engagement for fibrin-rich clot after deployment of the stent retriever and enable corking at the tip of the DAC or BGC prior to retrieval of the entire system. Additionally, the FPS reported here with the BGC is higher than the DAC and sheath for all groups (Fig. 2) which also supports improved patient outcomes (lower mRS scores and higher first pass effect) reported clinically with BGC use [8].

The following limitations of the in vitro study should be noted. The FPS testing performed for this study was designed to simulate a single-sided ICA-MCA-ACA model with limited collateral flow. To enable effective 1:1 comparisons for FPS between stent retriever lengths, several assumptions were made in this study: (a) lack of full circle of Willis limits extensive flow collateralization; (b) viscosity of the fluid was similar to water (incorporation of soap is essential to mimic the friction between the stent and vessel wall and is not feasible when using glycerol); (c) homogeneous fully occlusive cylindrical shaped clots were used; (d) the DAC option was primarily used (since there is no flow arrest and potential for the clot to disengage from the stent retriever is higher); and (e) placement of the DAC at the ICA-T bifurcation (this is the clinical worst case if the DAC cannot be advanced to be en face with the clot in the MCA).

Although the clot tends to disengage with both devices during retrieval, the longer device helps maintain engagement until the clot is captured or corked at the tip of the DAC. The additional stent length is also relevant for retrieval of large clots at the ICA-T bifurcation, particularly in the case of BGC use, where the stent-clot engagement needs to be maintained until the system is retrieved up to the proximal ICA (location of the BGC). All these factors collectively result in demonstrating a higher FPS for the longer 6-mm diameter stent retrievers in this bench model.

\section{Conclusion}

The in vitro portion of the present study suggests a significantly higher FPS with the $6 \times$ $40 \mathrm{~mm}$ Solitaire ${ }^{\mathrm{TM}}$ device compared to the $6 \times 30 \mathrm{~mm}$ Solitaire ${ }^{\mathrm{TM}}$ device in fibrin-rich clot retrieval. The in vivo portion of this study seems to indicate that the $6 \times 40 \mathrm{~mm}$ Solitaire $^{\mathrm{TM}}$ device has a non-inferior vascular safety profile compared to the $6 \times 30 \mathrm{~mm}$ Solitaire ${ }^{\mathrm{TM}}$ device.

\section{Statement of Ethics}

Animal experiments conform to internationally accepted standards and have been approved by the appropriate institutional review body.

\section{Disclosure Statement}

Dr. Amon Y. Liu and Dr. Italo Linfante are consultants for Medtronic.

\section{References}

1 Berkhemer OA, Fransen PS, Beumer D, van den Berg LA, Lingsma HF, Yoo AJ, et al.; MR CLEAN Investigators. A randomized trial of intraarterial treatment for acute ischemic stroke. N Engl J Med. 2015 Jan;372(1):11-20.

2 Campbell BC, Mitchell PJ, Kleinig TJ, Dewey HM, Churilov L, Yassi N, et al.; EXTEND-IA Investigators. Endovascular therapy for ischemic stroke with perfusion-imaging selection. N Engl J Med. 2015 Mar;372(11):1009-18.

3 Goyal M, Demchuk AM, Menon BK, Eesa M, Rempel JL, Thornton J, et al.; ESCAPE Trial Investigators. Randomized assessment of rapid endovascular treatment of ischemic stroke. N Engl J Med. 2015 Mar;372(11):1019-30. 
4 Jovin TG, Chamorro A, Cobo E, de Miquel MA, Molina CA, Rovira A, et al.; REVASCAT Trial Investigators. Thrombectomy within 8 hours after symptom onset in ischemic stroke. N Engl J Med. 2015 Jun;372(24):2296-306.

5 Saver JL, Goyal M, Bonafe A, Diener HC, Levy EI, Pereira VM, et al.; SWIFT PRIME Investigators. Stent-retriever thrombectomy after intravenous t-PA vs. t-PA alone in stroke. N Engl J Med. 2015 Jun;372(24):2285-95.

6 Nogueira RG, Jadhav AP, Haussen DC, Bonafe A, Budzik RF, Bhuva P, et al.; DAWN Trial Investigators. Thrombectomy 6 to 24 Hours after Stroke with a Mismatch between Deficit and Infarct. N Engl J Med. 2018 Jan; 378(1):11-21.

7 Albers GW, Marks MP, Kemp S, Christensen S, Tsai JP, Ortega-Gutierrez S, et al.; DEFUSE 3 Investigators. Thrombectomy for Stroke at 6 to 16 Hours with Selection by Perfusion Imaging. N Engl J Med. 2018 Feb; 378(8):708-18.

8 Zaidat OO, Castonguay AC, Linfante I, Gupta R, Martin CO, Holloway WE, et al. First Pass Effect: A New Measure for Stroke Thrombectomy Devices. Stroke. 2018 Mar;49(3):660-6.

9 Liebeskind DS, Sanossian N, Yong WH, Starkman S, Tsang MP, Moya AL, et al. CT and MRI early vessel signs reflect clot composition in acute stroke. Stroke. 2011 May;42(5):1237-43.

10 Gunning GM, McArdle K, Mirza M, Duffy S, Gilvarry M, Brouwer PA. Clot friction variation with fibrin content; implications for resistance to thrombectomy. J Neurointerv Surg. 2018 Jan;10(1):34-8.

11 Fennell VS, Setlur Nagesh SV, Meess KM, Gutierrez L, James RH, Springer ME, et al. What to do about fibrin rich 'tough clots'? Comparing the Solitaire stent retriever with a novel geometric clot extractor in an in vitro stroke model. J Neurointerv Surg. 2018 Sep;10(9):907-10.

12 Chueh JY, Puri AS, Gounis MJ. An in vitro evaluation of distal emboli following Lazarus Cover-assisted stent retriever thrombectomy. J Neurointerv Surg. 2017 Feb;9(2):183-7.

13 Chueh JY, Puri AS, Wakhloo AK, Gounis MJ. Risk of distal embolization with stent retriever thrombectomy and ADAPT. J Neurointerv Surg. 2016 Feb;8(2):197-202.

14 Chueh JY, Wakhloo AK, Gounis MJ. Effectiveness of mechanical endovascular thrombectomy in a model system of cerebrovascular occlusion. AJNR Am J Neuroradiol. 2012 Nov;33(10):1998-2003.

15 Gounis MJ, Wakhloo AK, Chueh JY. Preclinical investigations for thrombectomy devices-does it translate to humans? Stroke. 2013 Jun;44(6 Suppl 1):S7-10.

16 Mokin M, Ionita CN, Nagesh SV, Rudin S, Levy EI, Siddiqui AH. Primary stentriever versus combined stentriever plus aspiration thrombectomy approaches: in vitro stroke model comparison. J Neurointerv Surg. 2015 Jun; $7(6): 453-7$

17 Mokin M, Setlur Nagesh SV, Ionita CN, Levy EI, Siddiqui AH. Comparison of modern stroke thrombectomy approaches using an in vitro cerebrovascular occlusion model. AJNR Am J Neuroradiol. 2015 Mar;36(3):54751.

18 Mokin M, Setlur Nagesh SV, Ionita CN, Mocco J, Siddiqui AH. Stent retriever thrombectomy with the Cover accessory device versus proximal protection with a balloon guide catheter: in vitro stroke model comparison. J Neurointerv Surg. 2016 Apr;8(4):413-7.

19 Wainwright JM, Jahan R. Solitaire FR revascularization device $4 \times 40$ : safety study and effectiveness in preclinical models. J Neurointerv Surg. 2016 Jul;8(7):710-3.

20 Haussen DC, Al-Bayati AR, Grossberg JA, Bouslama M, Barreira C, Bianchi N, et al. Longer stent retrievers enhance thrombectomy performance in acute stroke. J Neurointerv Surg. 2019 Jan;11(1):6-8.

21 Chueh JY, Wakhloo AK, Hendricks GH, Silva CF, Weaver JP, Gounis MJ. Mechanical characterization of thromboemboli in acute ischemic stroke and laboratory embolus analogs. AJNR Am J Neuroradiol. 2011 Aug;32(7): 1237-44.

22 Kamalian S, Morais LT, Pomerantz SR, Aceves M, Sit SP, Bose A, et al. Clot length distribution and predictors in anterior circulation stroke: implications for intra-arterial therapy. Stroke. 2013 Dec;44(12):3553-6.

23 Gory B, Bresson D, Rouchaud A, Yardin C, Mounayer C. A novel Swine model to evaluate arterial vessel injury after mechanical endovascular thrombectomy. Interv Neuroradiol. 2013 Jun;19(2):147-52.

24 Gory B, Bresson D, Kessler I, Perrin ML, Guillaudeau A, Durand K, et al. Histopathologic evaluation of arterial wall response to 5 neurovascular mechanical thrombectomy devices in a swine model. AJNR Am J Neuroradiol. 2013 Nov-Dec;34(11):2192-8.

25 Singh P, Doostkam S, Reinhard M, Ivanovas V, Taschner CA. Immunohistochemical analysis of thrombi retrieved during treatment of acute ischemic stroke: does stent-retriever cause intimal damage? Stroke. 2013 Jun;44(6):1720-2.

26 Peschillo S, Diana F, Berge J, Missori P. A comparison of acute vascular damage caused by ADAPT versus a stent retriever device after thrombectomy in acute ischemic stroke: a histological and ultrastructural study in an animal model. J Neurointerv Surg. 2017 Aug; 9(8):743-9.

27 Lapergue B, Blanc R, Gory B, Labreuche J, Duhamel A, Marnat G, et al.; ASTER Trial Investigators. Effect of Endovascular Contact Aspiration vs Stent Retriever on Revascularization in Patients With Acute Ischemic Stroke and Large Vessel Occlusion: The ASTER Randomized Clinical Trial. JAMA. 2017 Aug;318(5):443-52. 